\title{
Ferramentas para a compreensão do conhecimento tácito de indivíduos
}

Tools for understanding the tacit knowledge of individuals

\section{Debora Barauna}

Universidade do Vale do Rio dos Sinos - Unisinos

debora.barauna1@gmail.com

$x$

André Luis Orthey

Universidade Federal do Paraná

mcorthey@gmail.com

XI

Silvana Souza Silvério

Universidade do Estado de Santa Catarina

silvana.silverio@madeiroteca.com.br

Michele Tais D. C. Zamoner

Universidade Federal do Paraná

mizamoner@gmail.com

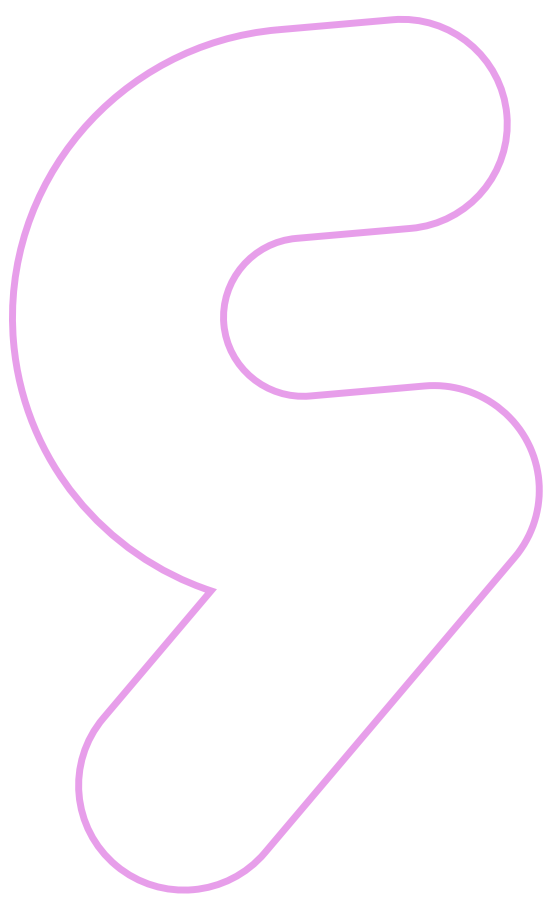

Dalton Luiz Razera

Universidade Federal do Paraná

daltonrazera@ufpr.br

\section{PROJËTICA}

\section{COMO CITAR ESTE ARTIGO:}

BARAUNA, D.; ORTHEY, A. L.; SILVÉRIO, S. S.; ZAMONER, M. T. D. C.; RAZERA, D. L. Ferramentas para a compreensão do conhecimento tácito de indivíduos. Projética, Londrina, v. 11, n. 1, p 194-219, 2020.

DOI: 10.5433/2236-2207.2020v11n1p194

Submissão: 07-01-2019

Aceite: 31-05-2019 
Ferramentas para a compreensão do conhecimento tácito de indivíduos

BARAUNA, D. et al.

RESUMO: Este estudo analisou o potencial de combinação das ferramentas, jogo de perguntas pessoais, mapa de empatia e storytelling, na compreensão do conhecimento tácito de indivíduos. As ferramentas propostas foram aplicadas para uma amostra de 28 participantes. Os dados obtidos foram interpretados como características pessoais e relacionais dos indivíduos. Os resultados mostraram que as ferramentas foram complementares na compreensão breve dos conhecimentos tácitos dos participantes, que refletiram sobre si próprios, sobre o seu contexto e a sua história.

Palavras-chave: Criação de conhecimento. Espiral do conhecimento. Socialização. Conhecimento prévio.

ABSTRACT: The objective of this study is to evaluate the potential of combining tools game of personal questions, empathy map and storytelling - in understanding the tacit knowledge of individuals. The study was applied to a sample of 28 participants, and the data collected were interpreted as personal and relational characteristics of the individuals. Results show that the tools were complementary in the brief understanding of participants' tacit knowledge, who had the chance to reflect on themselves, their context and their history.

Keywords: Knowledge construction. Knowledge spiral. Socialization. Previous knowledge.

\section{INTRODUÇÃO}

A criação de conhecimento, quando compreendida pela espiral do conhecimento de Nonaka e Konno (1998), é um processo que demanda da atividade de socialização, com a interação entre conhecimentos tácitos de indivíduos. O 
Projética, Londrina, v.11, n.1, p. 194-219, abril 2020

conhecimento tácito é um tipo de conhecimento pessoal, baseado em experiências vividas, que só se revela na ação e que é de difícil socialização, conforme embasam Santos et al. (2001) e Silva (2004).

Desta forma, o objetivo deste estudo foi analisar o potencial da combinação de três ferramentas (jogo de perguntas pessoais, mapa de empatia e storytelling) na compreensão do conhecimento tácito de indivíduos. Para tanto, foram realizadas três práticas de aplicação das ferramentas propostas para três grupos distintos. A amostra total do estudo foi de 28 indivíduos, sendo que, 10 eram discentes de uma disciplina de pós-graduação stricto sensu da Universidade Federal do Paraná (UFPR), na qual foi aplicada um piloto. Os demais participantes (18 indivíduos) eram profissionais ou convidados de dois grupos de ciência, tecnologia e inovação (CT\&l) de duas outras universidades brasileiras. Os dados coletados sobre os conhecimentos tácitos dos indivíduos foram analisados e descritos como características pessoais e relacionais em um quadro do perfil de cada participante. Todos os perfis receberam feedback positivo dos participantes.

Enfim, na sequência, o tema do estudo é fundamentado bem como o método de pesquisa aplicado é detalhado e os resultados obtidos são apresentados e discutidos.

\section{FUNDAMENTAÇÃO TEÓRICA}

Organizações contemporâneas têm se reinventado, por meio de uma nova cultura de cooperação e sinergia entre pessoas, para a promoção de trocas de informações e criação de conhecimento: as pessoas são postas em circuitos de feedback, para que suas ideias, raciocínios e sensações possam ser percebidos (TORQUATO; WILLERDING; LAPOLLI, 2015). 
Ferramentas para a compreensão do conhecimento tácito de indivíduos

BARAUNA, D. et al.

Entende-se organização como um sistema socialmente estabelecido pelo conjunto de partes que a integram e interagem influenciando-se mutuamente na direção da realização de objetivos e resultados comuns (COLOSSI; BAADE, 2015). As organizações são também "sistemas de informações, onde a comunicação é o processo social" (COLOSSI; BAADE, 2015, p. 17). Neste contexto, tem-se que a criação de conhecimento demanda da capacidade dos indivíduos de "interpretar e operar sobre um conjunto de informações" (HASHIMOTO, 2003, p. 2). Essa capacidade é criada a partir das relações que são estabelecidas pelos conhecimentos prévios dos indivíduos, aqueles já adquiridos ou que lhe são familiares, incluindo experiências, impressões, valores, crenças, etc. (HASHIMOTO, 2003). Logo, quanto mais indivíduos atuarem juntos, maior será a capacidade de gerar interpretações e criar conhecimento nas organizações. É desta forma que a espiral do conhecimento de Nonaka e Konno (1998) destaca a atividade de socialização como o ponto de partida do processo de criação de conhecimento.

Na espiral do conhecimento (Figura 1) conceitos fundamentais envolvem a relação entre os conhecimentos tácitos e explícitos de indivíduos, em grupo e na organização. O conhecimento tácito, como já previamente introduzido, é um "conhecimento subjetivo; habilidades inerentes a uma pessoa; sistema de ideias, percepção e experiência; difícil de ser formalizado, transferido ou explicado a outra pessoa" (SILVA, 2004, p. 145). Trata-se de um tipo de "conhecimento pessoal incorporado à experiência individual e que envolve fatores intangíveis como, por exemplo, crenças pessoais, perspectivas, sistema de valor, insights, intuições, emoções e habilidades. [...] Só pode ser avaliado por meio da ação" (SANTOS et al., 2001, p. 30). Já o conhecimento explícito é aquele "passível de verbalização e registro" (SILVA, 2004, p. 143) pode ser facilmente articulado, transmitido, sistematizado e comunicado pela linguagem formal entre os indivíduos, no formato de textos; expressões matemáticas; especificações; manuais; gráficos; tabelas; figuras; desenhos; esquemas; diagramas etc. (SANTOS et al., 2001; SILVA, 2004). Esses dois tipos de conhecimento relacionam-se por completo na espiral 
Projética, Londrina, v.11, n.1, p. 194-219, abril 2020

do conhecimento (Figura 1) diante das atividades de socialização, externalização, combinação e internalização.

Figura 1 - Espiral do conhecimento.

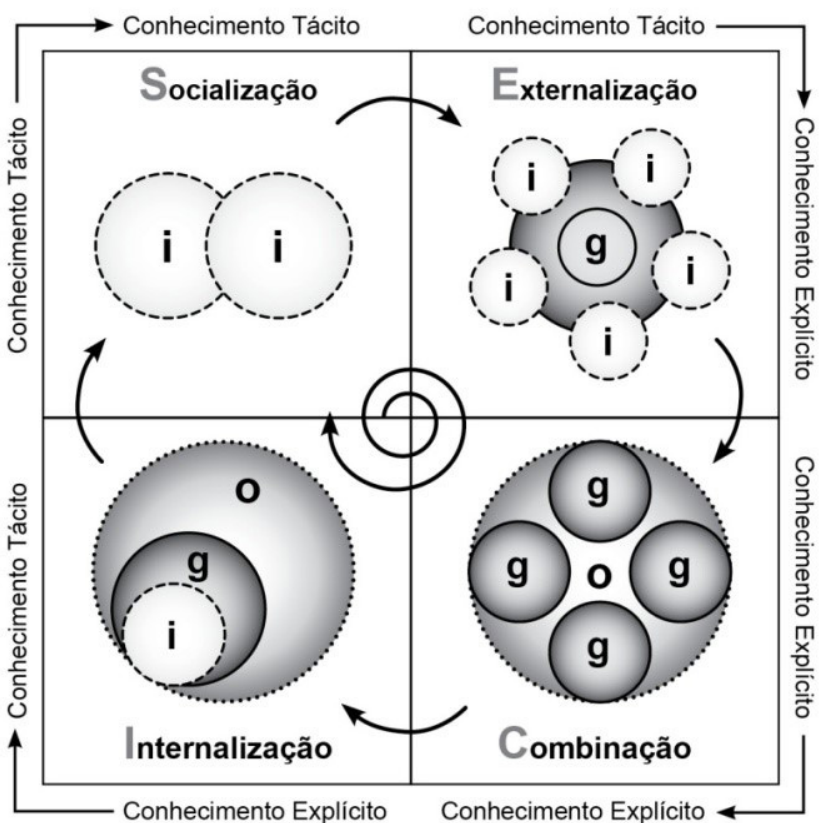

(i) indivíduo (g) grupo o organização

Fonte: Adaptado de Nonaka e Konno (1998).

$\mathrm{Na}$ atividade de socialização ocorre a interação, o diálogo, entre os conhecimentos tácitos dos indivíduos. Na atividade de externalização os conhecimentos tácitos são convertidos em explícitos, por meio do uso de ferramentas diversas, entre indivíduos de um grupo. Já na atividade de combinação acontece a interação entre os conhecimentos explícitos gerados pela sistematização da informação na organização. Por último, na internalização o novo conhecimento explícito sistematizado é incorporado nas práticas da organização e passa por 
Ferramentas para a compreensão do conhecimento tácito de indivíduos

BARAUNA, D. et al.

processos de reflexão e experimentação do indivíduo, que, com isso, adquire um novo conhecimento tácito. A Figura 2 especifica essas atividades, diante de seus conceitos e formatos de realização, além de técnicas que podem contribuir para a realização de cada uma dessas atividades.

Figura 2- Atividades da espiral do conhecimento.

\begin{tabular}{|c|c|}
\hline Socialização & Externalização \\
\hline $\begin{array}{l}\text { Conceito: compartilhamento do conhecimento tácito ou } \\
\text { troca de experiências prévias. } \\
\text { Formato: ocorre por meio da observação, imitação ou } \\
\text { prática entre pessoas. } \\
\text { Técnicas: diálogo, brainstorming (insights e intuições), } \\
\text { construção de modelos mentais entre outros. }\end{array}$ & $\begin{array}{l}\text { Conceito: é a conversão do conhecimento tácito } \\
\text { em explícito. } \\
\text { Formato: ocorre pela comunicação em grupo. } \\
\text { Técnicas: descritivas em planilhas, textos, imagens, } \\
\text { figuras, regras, scripts, storytelling, storybording e } \\
\text { relatos audiovisuais. }\end{array}$ \\
\hline Internalização & Combinação \\
\hline $\begin{array}{l}\text { Conceito: é quando novos conhecimentos explícitos são } \\
\text { incorporados na organização, reinterpretados e } \\
\text { reexeperimentados. } \\
\text { Formato: ocorre pela reflexão, vivências e práticas. } \\
\text { Técnicas: relatórios, verbalização, diagramas e guias. }\end{array}$ & $\begin{array}{l}\text { Conceito: é quando o conhecimento é sistematizado. } \\
\text { Formato: ocorre por sistemas de conceitos. } \\
\text { Técnicas: framework, diretrizes, protótipos e } \\
\text { modelos mentais. }\end{array}$ \\
\hline
\end{tabular}

Fonte: Baseada em Nonaka e Konno (1998), Santos et al. (2001) e Silva (2004).

A espiral do conhecimento apresenta o conhecimento tácito como um componente essencial para o processo de criação de conhecimento. Ao longo deste processo, pelo menos dois fatores tendem a demonstrar isto, tais como:

1. Primeiro, devido à criação de conhecimento depender da atividade inicial de socialização entre os conhecimentos tácitos dos indivíduos (NONAKA; KONNO, 1998; SANTOS et al., 2001; SILVA, 2004; ZANGISKI; LIMA; COSTA, 2009).

2. Segundo, porque, na continuidade do processo, novas relações se dão por meio da conexão entre os conhecimentos tácitos e explícitos dos indivíduos em grupo e nas organizações (FLEURY; FLEURY, 2001; NONAKA; KONNO, 1998; ZANGISKI; LIMA; COSTA, 2009).

3. Terceiro, tendo em vista que a criação de conhecimento resulta da aprendizagem, que por sua vez demanda da relação entre os conhecimentos prévios dos indivíduos, aqueles adquiridos ao longo da vida, logo do conhecimento tácito 
Projética, Londrina, v.11, n.1, p. 194-219, abril 2020

(BATOCCHIO; BIAGIO, 1999; BEBER; SILVA; BONFIGLIO, 2014; COUTINHO; LISBÔA, 2011; DÍAZ, 2011; FABELA, 2005; FLEURY; FLEURY, 2001; GASQUE; TESCAROLO, 2004; MOREIRA, 2012; NONATO, 2009; POZO, 2002, 2007; REICHERT, 2002; SANTOS et al., 2001; SILVA, 2004; VASCONCELLOS, 2011; ZANGISKI; LIMA; COSTA, 2009). Beber, Silva e Bonfiglio (2014) explicam que o conhecimento prévio é determinante para a aprendizagem, já que serve de alicerce para a assimilação e compreensão do conhecimento.

Tendo sido apresentada as principais bases teóricas que fundamentaram o estudo, na sequência descreve-se o método de pesquisa aplicado.

\section{MÉTODO DE PESQUISA}

Este estudo caracterizou-se como uma pesquisa de campo de abordagem qualitativa. Os procedimentos adotados foram: pesquisa bibliográfica e documental, observação participante e feedback. Os estágios, denominados, construir, avaliar e aprender, do processo de prototipagem da ideia de Ries (2011) foram aplicados para orientar as etapas de condução da pesquisa.

\subsection{Construção da Ideia}

A construção da ideia partiu da pesquisa bibliográfica, que levou à realização de uma pesquisa documental sobre possíveis dinâmicas, ferramentas, técnicas e métodos capazes de extrair o conhecimento tácito dos indivíduos. As ferramentas selecionadas foram autoapresentação com jogo de perguntas pessoais, mapa de empatia e stotytelling, além de pesquisa em redes sociais.

A autoapresentação é uma técnica em que um indivíduo apresenta-se para um grupo, falando de si, situando-se no seu contexto e sobre os papéis que desempenha na sua vida. Para uso desta técnica sugeriu-se o formato em roda, 
Ferramentas para a compreensão do conhecimento tácito de indivíduos

BARAUNA, D. et al.

em que cada participante, inicialmente, comunicou o seu nome e a sua profissão e em seguida escolheu (a cega) uma pergunta pessoal, o que foi determinado de jogo de perguntas pessoais. A intenção da aplicação desta ferramenta foi gerar um processo de autoconhecimento e de conhecimento mútuo entre os participantes. Para isto, as seguintes perguntas foram utilizadas:

1. Quais são as suas crenças e valores?

2. Quais os eventos mais importantes na definição da sua personalidade?

3. O que faz você agir da maneira que age?

4. Qual o sentido das ideias que guiam sua vida?

5. Qual o roteiro do filme da sua vida?

6. O que você tem de valor pessoal que ninguém sabia até hoje?

7. Como se formaram os seus ideais e porque você os segue?

8. O que motiva você a aprender?

9. Conte um momento especial de sua vida?

Já o mapa de empatia é uma ferramenta que possibilita obter dados relacionados sobre o que um indivíduo pensa, fala, vê e ouve, além de suas dores e necessidades. O mapa de empatia é comumente usado pelo design para aprender com a experiência do usuário e o contexto, olhando para fora do processo. Neste estudo, a proposta foi que os usuários olhassem para dentro de si e do seu próprio contexto. Para a aplicação do mapa de empatia também foi atribuída algumas perguntas sugestivas para a autorreflexão dos participantes, conforme expõe a Figura 3.

Por fim, a Storytelling constitui-se como uma importante ferramenta para o compartilhamento de valores sociais dos indivíduos, considerando que, por meio desta, suas histórias - story são narradas - telling (SALMON, 2008). Assim, a perspectiva de uso da storytelling considerou que os participantes poderiam contar as suas experiências obtidas ao longo da vida. 
Projética, Londrina, v.11, n.1, p. 194-219, abril 2020

Entretanto, tendo para isto, um tempo (20 min) e espaço físico (1 lauda) específico. Algumas questões também apoiaram o desenvolvimento desta ferramenta, conforme mostra a Figura 4.

Figura 3 - Mapa de empatia e perguntas de apoio.

\begin{tabular}{|c|c|}
\hline $\begin{array}{l}\text { O que você pensa e sente? } \\
\text { Quais são algumas ideias } \\
\text { importantes que você pensa e não diz? } \\
\text { Como você se sente em relação à vida? } \\
\text { Com o que tem se preocupado? } \\
\text { Quais são alguns dos seus sonhos? }\end{array}$ & $\begin{array}{r}\text { O que você vê? } \\
\text { Como é o mundo em que você vive? } \\
\text { O que as pessoas que o rodeiam fazem? } \\
\text { Como são os seus amigos? } \\
\text { O que está em alta no seu cotidiano? }\end{array}$ \\
\hline $\begin{array}{l}\text { O que você ouve? } \\
\text { Que pessoas e ideais o influenciam? } \\
\text { O que as pessoas importantes de } \\
\text { sua vida dizem? } \\
\text { Que atitude tem as suas marcas? } \\
\text { Quem são seus ídolos? }\end{array}$ & $\begin{array}{r}\text { O que você fala e faz? } \\
\text { O que é comum de você dizer? } \\
\text { Como você costuma agir? } \\
\text { Quais são os seus hobbies? } \\
\text { O que gosta de falar? }\end{array}$ \\
\hline $\begin{array}{l}\text { Quais são as suas DORES? } \\
\text { O que você tem medo? } \\
\text { O que o frustra? } \\
\text { O que tem atrapalhado você? } \\
\text { O que você gostaria de mudar em sua vida? }\end{array}$ & $\begin{array}{r}\text { Quais são as suas NECESSIDADES? } \\
\text { O que você precisa para se sentir bem? } \\
\text { O que é sucesso? Onde você quer chegar? } \\
\text { O que tem feito para ser feliz? } \\
\text { O que acabaria com suas dores? }\end{array}$ \\
\hline
\end{tabular}

Fonte: Baseada em Gray (2009).

Figura 4 - Questões orientativas sobre a storytelling.

Quais foram as suas escolhas, os seus conflitos, os problemas e desafios que enfrentou, as consequências e o aprendizado com os erros cometidos e, finalmente, qual a mudança que tudo isto proporcionou em sua vida?

Data: Título:

Fonte: Desenvolvida pelos autores (2016). 
Ferramentas para a compreensão do conhecimento tácito de indivíduos BARAUNA, D. et al.

$\mathrm{Na}$ espiral do conhecimento [...] conceitos fundamentais envolvem a relação entre os conhecimentos tácitos e explícitos de indivíduos, em grupo e na organização. o conhecimento tácito, como já previamente introduzido, é um "conhecimento subjetivo; habilidades inerentes a uma pessoa; sistema de ideias, percepção e experiência; difícil de ser formalizado, transferido ou explicado a outra pessoa" (SILVA, 2004, p. 145).

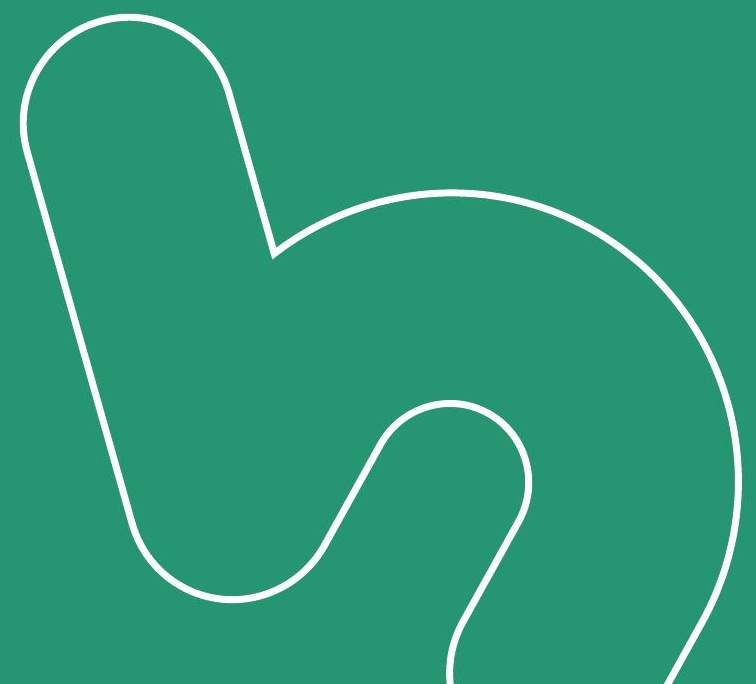


Projética, Londrina, v.11, n.1, p. 194-219, abril 2020

Enfim, o potencial de combinação dessas ferramentas foi avaliado, primeiro, por meio de uma aplicação piloto em ambiente interno e mais duas aplicações em ambiente externo.

\subsection{Avaliação da Ideia}

No estágio de avaliação, as ferramentas selecionadas foram aplicadas para 28 profissionais de universidades brasileiras (no decorrer do estudo os nomes dos participantes foram determinados como A, B, C etc. e relacionados ao ano da aplicação, piloto em 2016 e ambientes em 2017). Os dados dos participantes coletados neste estágio foram analisados diante da combinação das ferramentas aplicadas para a compreensão dos conhecimentos tácitos dos indivíduos envolvidos no processo.

Na aplicação piloto o objetivo foi avaliar rapidamente da ideia. Isto ocorreu mediante uma amostra de 10 discentes, de uma disciplina do Programa de PósGraduação em Design da UFPR, caracterizada por 9 mulheres e 1 homem, com média de idade de 32 anos. A formação em ensino superior desses discentes eram de 8 indivíduos em design, 1 em artes visual e 1 em publicidade; 1 participante era mestre e os demais ainda almejavam essa formação. A área de atuação dos participantes era, na sua maioria, em design como freelance, 2 eram professores e 1 tinha uma empresa de design. Todos os participantes eram de origem brasileira, sendo que 5 indivíduos tinham vivido experiências em diferentes culturas brasileiras e 3 em culturas internacionais por meio de programas de intercâmbio.

A aplicação piloto ocorreu com a realização de um encontro de 3 horas de duração. O encontro foi iniciado com a apresentação da finalidade da prática, de modo expositivo (recursos visuais) e dialogado, para motivar os participantes para o processo. A ferramenta seguinte aplicada foi a stotytelling. A introdução desta ferramenta foi apoiada pelo uso de recursos visuais. Na sequência, a 
Ferramentas para a compreensão do conhecimento tácito de indivíduos

BARAUNA, D. et al.

introdução do jogo de perguntas pessoais aconteceu de modo dialogado, por meio da autoapresentação. As respostas dadas pelos participantes no jogo de perguntas pessoais foram gravadas com o auxílio de um programa de multimídia em notebook. A última ferramenta aplicada foi o mapa de empatia, que também foi conduzido pelo uso de recursos visuais.

Após o piloto, as aplicações em ambiente externo das ferramentas aconteceram para dois grupos de ciência, tecnologia e inovação (CT\&l) de duas outras universidades brasileiras. O total da amostra de participantes dessas duas aplicações foi de 18 indivíduos, conforme segue:

O primeiro grupo, da Universidade Federal de Santa Catarina (UFSC) caracterizou-se por 4 mulheres e 5 homens, em sua maioria doutores, com formações variadas: engenharia química, biologia, farmácia, medicina, odontologia, educação e design. Os setores de atuação desses profissionais eram em inovação na área de saúde; qualidade; design; bioengenharia e biomateriais. A média de idade desses participantes era de 45 anos.

O grupo seguinte, da Universidade da Região de Joinville (UNIVILLE) caracterizou-se por 7 mulheres e 2 homens, também em sua maioria doutores com formações variadas: química, engenharia química, engenharia de alimentos, educação, direito e design. Os setores de atuação destes profissionais eram em gestão da inovação; design; orientação de projetos e pesquisa em microbiologia, biopolímeros e engenharia química. A média de idade deste grupo era de 42 anos.

O tempo previsto para ambas as aplicações foi de 3 horas de duração para cada grupo. Os recursos utilizados foram multimídias e um guia de coleta de dados dos participantes, contendo: termo de consentimento livre esclarecido e ferramentas para coleta de dados dos conhecimentos tácitos dos participantes (jogo de perguntas pessoais, mapa de empatia e storytelling). 
Projética, Londrina, v.11, n.1, p. 194-219, abril 2020

Nas aplicações em ambiente externo foi alterada a ordem de aplicação das ferramentas, primeiro foi realizado o jogo de perguntas pessoais, seguido do mapa de empatia e storytelling. O objetivo foi avaliar o potencial da nova sequência das ferramentas sobre o processo de encadeamento das ideias dos participantes.

No estágio seguinte, de prototipagem da ideia, é descrito como ocorreu a aprendizagem sobre essas aplicações realizadas.

\subsection{Aprendizagem Sobre a Ideia}

Neste estágio foi possível aprender sobre a ideia, por meio da observação participante, do recebimento de feedback e da análise gerada com a combinação das ferramentas. Durante as aplicações realizadas foi observada a fluidez das ferramentas de coleta de dados sobre o conhecimento tácito dos participantes, considerando a dinâmica de aplicação, o encadeamento das ideias, o tempo de aplicação das ferramentas bem como o entendimento da forma de uso de cada ferramenta pelos participantes.

Como suporte ao ponto de vista do pesquisador-observador foi utilizado um diário de campo, contendo os seguintes espaços para registro da observação: número; data; local; tempo, fato; observador; descrição geral e outras percepções. Também auxiliou na observação um profissional mestre em design com graduação na área de educação, o que permitiu discutir pontos de vista distintos da observação.

Os dados coletados foram interpretados e combinados em um quadro do perfil prévio de cada participante. Foi solicitado aos participantes que esses avaliassem as informações contidas no quadro e comentassem sobre a composição gerada. Sobretudo, foi verificado o potencial de combinação das ferramentas determinadas na extração de diferentes visões quanto ao conhecimento tácito de indivíduos. 
Ferramentas para a compreensão do conhecimento tácito de indivíduos

BARAUNA, D. et al.

Enfim, partindo da observação participante e do feedback obtido sobre a aplicação piloto, foram atribuídas algumas recomendações para as duas aplicações, seguintes, em ambiente externo. Os resultados deste processo de avaliação são relatados e discutidos na sequência.

\section{RESULTADOS E DISCUSSÃO}

Os resultados obtidos no estudo são apresentados, a seguir, considerando primeiro a aplicação piloto e suas recomendações de melhorias para as aplicações em ambiente externo, que são descritos e discutidas na sequência.

\subsection{Aplicação Piloto}

Com a análise dos dados obtidos na aplicação piloto foi possível classificar os conhecimentos prévios dos participantes em características pessoais e relacionais. As principais informações que determinaram as características pessoais dos participantes foram comportamentos; valores; aprendizagem continua. Já as características relacionais foram enfatizas por comportamentos de criação de laços emocionais, experiências culturais e consciência da relação mundo-indivíduo. O Quadro 1 exemplifica como o perfil prévio dos participantes foi apresentado para a obtenção de feedback.

Todos os participantes validaram o seu perfil e alguns realizaram comentários, conforme segue: "Fiquei surpresa com a avaliação! Bem compatível!" (PARTICIPANTE C, 2016). "Acredito que a avaliação segue aquilo que considero serem minhas características como pessoa no mundo" (PARTICIPANTE D, 2016). "Acredito que a avaliação gerada condiz com o meu perfil, porém quando colocado no papel gera certo estranhamento mesmo que essas informações sejam sobre mim elas soam como se não me pertencessem, pois parecem que enaltecem meus aspectos positivos e ocultam minhas falhas (PARTICIPANTE E, 2016). 
Projética, Londrina, v.11, n.1, p. 194-219, abril 2020

“No geral, super interessante o feedback. Realmente é o meu perfil pessoal e profissional. Um grande trabalho que tem um 'fundo' super sensível, onde trabalha com um lado não trabalhado das pessoas, o emocional" (PARTICIPANTE F, 2016).

Quadro 1 - Exemplo da apresentação do prévio dos participantes na aplicação piloto.

\begin{tabular}{|c|c|}
\hline Nome: Participante A (2016) & Idade: 39 anos \\
\hline \multicolumn{2}{|c|}{ CARACTERÍSTICAS } \\
\hline Pessoais & Relacionais \\
\hline $\begin{array}{l}\text { - Determinada, decidida e crítica } \\
\text { - Aprendizagem continua } \\
\text { - Valores: família, sua trajetória de vida, } \\
\text { territorialidade e liberdade de expressão } \\
\text { - Remete a mãe, que coloria fotografias, o } \\
\text { seu perfil artístico. } \\
\text { - Boa oralidade e demonstra interesse e } \\
\text { orgulho em contar sua história }\end{array}$ & $\begin{array}{l}\text { - Consciente (relação mundo } \mathrm{x} \text { indivíduo) } \\
\text { - Pertencimento (busca valor em suas raízes) } \\
\text { - Visão holística }\end{array}$ \\
\hline
\end{tabular}

Fonte: Desenvolvido pelos autores (2016).

Durante a análise, pelo recurso da memória, foi possível observar que as histórias contadas pelos participantes nas storytellings associavam-se com as memórias guardadas sobre esses, diante das dinâmicas de autoapresentação e jogo de perguntas pessoais realizados. Este foi o primeiro indicativo da compatibilidade de combinação das ferramentas. Somente a história de uma participante não gerou essa associação, o que confere com a sua característica pessoal 'retraída', observada tmbém na análise das demais ferramentas.

Enfim, os resultados obtidos evidenciaram a possibilidade de compreensão breve dos conhecimentos tácitos dos participantes Entretanto, para as aplicações seguintes, foi recomendado as seguintes melhorias: 
Ferramentas para a compreensão do conhecimento tácito de indivíduos

BARAUNA, D. et al.

1. Embora a ordem das ferramentas aplicadas no piloto (storytelling, jogo de perguntas pessoais e mapa de empatia) tenha demonstrado fluidez durante o processo, foi sugerido para as aplicações seguintes, começar a aplicação com o jogo de perguntas pessoais seguido do mapa de empatia e da storytelling. Esta mudança foi imaginada no sentido que o jogo de perguntas pessoais poderia contribuir para a motivação dos participantes no processo, tornando-os mais receptivos para as dinâmicas seguintes. Tendo em vista que, no piloto, o jogo de perguntas pessoas causou interação e descontração entre participantes. Também foi considerado que o mapa de empatia poderia auxiliar no processo de encadeamento das ideias na construção das histórias narradas (storytelling) em razão do preenchimento do mapa de empatia ser mais objetivo e referir-se a diferentes perspectivas de interação do indivíduo com mundo (o que vê, faz, fala e ouve).

2. Ainda sobre o jogo de perguntas pessoais foi observado que o tempo previsto para cada participante responder o questionamento deveria ser reduzido de 5 para 2 minutos e controlado para que a aplicação das dinâmicas seguintes não se tornasse inviável, como ocorreu no piloto, em que os itens 'dores' e 'necessidades' do mapa de empatia não foram completados por falta de tempo para a realização total da ferramenta.

3. Outra sugestão foi criar um documento único de aplicação, como um guia, contendo as ferramentas de coleta de dados sobre os conhecimentos tácitos, campos específicos para o registro de dados de identificação dos participantes (nome; idade; profissão e setor de atuação) e o termo de consentimento livre esclarecido sobre a coleta de dados.

Todas essas recomendações de melhorias foram aplicadas nas avaliações seguintes da prática, que aconteceram em ambiente externo, direcionadas para dois grupos de CT\&l do Brasil. 
Projética, Londrina, v.11, n.1, p. 194-219, abril 2020

\subsection{Aplicações em Ambiente Externo}

Referente às dinâmicas de aplicação das ferramentas em ambiente externo, o tempo estimado de 3 horas de aplicação foi suficiente, entretanto, foi preciso controlar o tempo a cada ferramenta aplicada.

No início da aplicação foi novamente realizado um breve diálogo sobre como ocorreria o processo. Em seguida foi realizado a autoapresentação com o jogo de perguntas pessoais. A partir dessa ferramenta, os participantes foram tornandose mais receptivos e motivados para a realização das demais ferramentas.

A ferramenta seguinte aplicada foi o mapa de empatia seguido da storytelling, tal como foi sugerido pela observação participante da aplicação piloto. Esta melhoria resultou em maior agilidade ao processo. O mapa de empatia forneceu uma base de informações para que os participantes desenvolvessem suas storytellings. Ainda durante a aplicação, o Participante F (2017) comentou que as ferramentas se complementavam.

Na Figura 5 mostra-se como ocorreu a análise interpretativa dos dados combinados pelas três ferramentas aplicadas.

A imagem demonstra que, diante das marcações em cores, palavras ou trechos dos textos (respostas) dos participantes foram cruzados e passaram por um processo de análise de semântica. Nesta análise, as ideias expostas pelos participantes foram compreendidas em um contexto e, com isso, permitiram a descoberta daquilo que estava implícito. Assim, foi possível atribuir significados aos conhecimentos tácitos dos indivíduos, que foram classificados ou sintetizados em características pessoais e relacionais. 


\section{Ferramentas para a compreensão do conhecimento tácito de indivíduos}

BARAUNA, D. et al.

Figura 5 - Ferramentas aplicadas e respostas da Participante A (2017).

\section{Jogo de Perguntas Pessoais}

\section{Jogo de Perguntas de Autoconhecimento [Qual foi a sua questão e resposta?]}

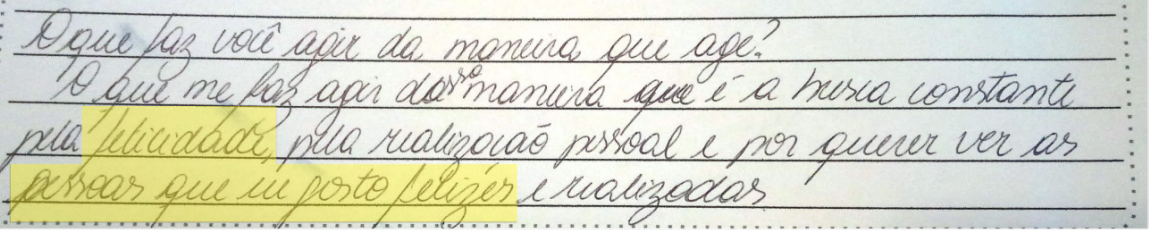

\section{Mapa de Emapatia}

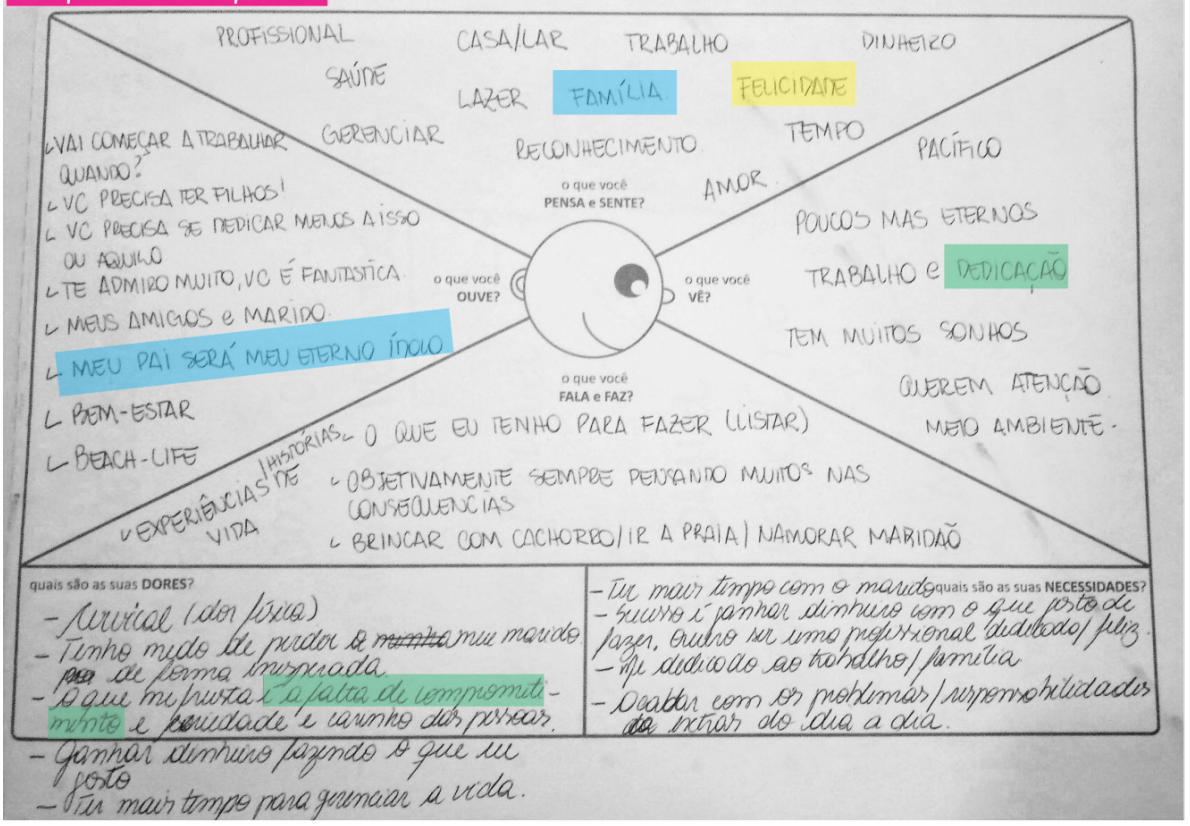

\section{Recortes do Storytelling}

distantir tentorialminte facondo Aersei tonpimharia Treimica na FURG (Fio fronde), considero um dos puíados mais detuis da minha vida pais nao me adopte a udade, mas fui persistente icondlii $\theta$ curso em 2005. Nunonte a universidade

\section{de aruas). A'mórte de mu pai no final' do mestrodo/Iniúio do doutorodo fai o exnto mair complexo da minha vida. He tomou uma pussoa mair hatulhodoral puerricale}

Fonte: Desenvolvida pelos autores (2017). 
Projética, Londrina, v.11, n.1, p. 194-219, abril 2020

Nas aplicações em ambiente externo, as principais informações que determinaram as características pessoais dos participantes foram: gosto de; não gosto de; buscas por realizações pessoais; valores e comportamentos, como, animado, dinâmico, divertido, curioso, tímido, dramático, expressivo, sensível, intenso, confuso, questionador, argumentativo, comprometido, determinado, organizado, perfeccionista, ousado, além de aprendizagem continua, medo de errar, enfretamento de situações adversas e insegurança em situações de incertezas. Já as características relacionais foram enfatizadas pelas buscas por realizações coletivas; capacidades (saber ouvir, empatia, gestão de conflitos, ações colaborativas e visão holística) e comportamentos de criação de laços emocionais com pessoas, experiências culturais, compaixão e consciência da relação mundoindivíduo. A Figura 6 exemplifica como essas características foram descritas em um mapa de perfil prévio dos participantes.

Figura 6 - Exemplo do mapa de perfil prévio da Participante A (2017).

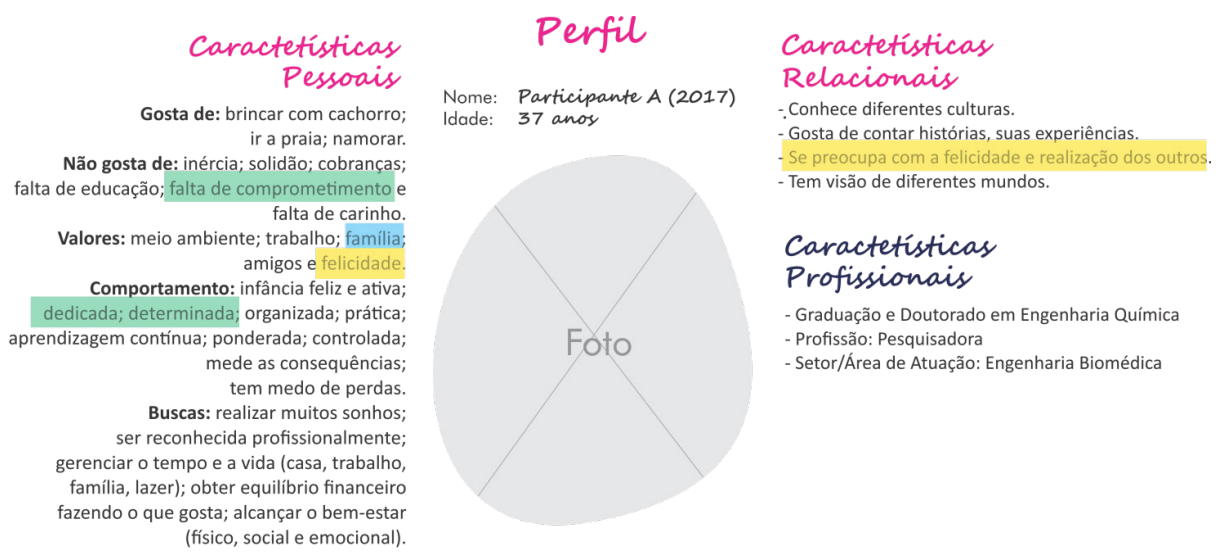

Fonte: Desenvolvida pelos autores (2017).

Neste exemplo, foi utilizado, mais uma vez, as mesmas marcações em cores, empregadas na Figura 5, visando evidenciar como aquelas informações foram sintetizadas no mapa de perfil prévio da Participante A (2017). 
Ferramentas para a compreensão do conhecimento tácito de indivíduos

BARAUNA, D. et al.

Essa forma de síntese foi fundamentada pelos modelos organizacionais baseados em competências, que demandam mapear o perfil dos atuais trabalhadores do conhecimento (ASSOCIAÇÃO BRASILEIRA DAS ENTIDADES FECHADAS DE PREVIDÊNCIA COMPLEMENTAR, 2013). Neste contexto, o agrupamento de competências pode ocorrer por características conceituais, técnicas e interpessoais. Kofman (2002 apud RUSSO; RUIZ; CUNHA, 2005) referese às características interpessoais como aquelas aplicadas à própria pessoa (objetividade ou autoconsciência, autoaceitação, autorregulação ou motivação, autoanálise, integridade e efetividade) e na relação com os outros (empatia, compaixão, influência, indagação e escuta). Uma vantagem observada, em se promover esse processo de síntese, foi que os mapas resultaram para os participantes em um olhar externo sobre eles, o que é diferente de simplesmente oferecer as ferramentas respondidas, por eles, para eles mesmo. Também, o mapa possibilita um conhecimento dinâmico de si próprio e dos demais participantes, podendo ser, facilmente, compartilhado entre os indivíduos de uma atividade de socialização.

Enfim, novamente, assim como na aplicação piloto, todos os participantes validaram os mapas dos seus perfis gerados. Alguns comentários recebidos foram:

1, “Concordo com todos os pontos [...] achei fantástico a montagem dos mapas dos indivíduos (PARTICIPANTE A, 2017).

2. "Representa bem o meu perfil" (PARTICIPANTE C, 2017)

3. "Achei bem apurado" (PARTICIPANTE F, 2017).

4. "Você me conhece" (PARTICIPANTES I; 2017).

5. "Gostei muito da oportunidade de autoconhecimento" (PARTICIPANTE J, 2017).

6. “Fidedigna” (PARTICIPANTE M, 2017). 
Projética, Londrina, v.11, n.1, p. 194-219, abril 2020

Desta forma, entende-se que o potencial de combinação das ferramentas propostas, para a compreensão dos conhecimentos tácitos de indivíduos, foi relevante, na medida em que essas ferramentas mostram-se complementares na análise, auxiliando no processo de reafirmação ou validação de informações, que se repetiam ou se assemelhavam em duas ou nas três ferramentas. Entretanto, cada ferramenta foi imaginada para um fim específico no processo. O propósito do jogo de perguntas pessoais, associado a uma dinâmica de autoapresentação, foi promover a abertura e interação dos participantes para o processo, bem como, exemplificar a complexidade das questões que seriam tratadas, relativas ao conhecimento tácito. Já o intuito do mapa de empatia foi trazer os indivíduos para dentro do seu contexto de vida e, com isso, gerar uma autoanálise. E, finalmente, o storytelling visou que os participantes refletissem sobre as suas próprias histórias.

Sobretudo, o uso das ferramentas propostas, para a compreensão dos conhecimentos tácitos de indivíduos, por organizações contemporâneas, antes da realização de práticas de criação de conhecimento, como em processos de aprendizagem, inovação, cocriação etc., pode facilitar a atividade de socialização da espiral do conhecimento. Assim como no caso das aplicações em ambientes externos deste artigo, em que o uso das ferramentas propostas, antecederam a realização de um processo de inovação, junto aos grupos de CT\&l participantes. Ao final deste processo de inovação, por meio de novo feedback solicitado aos participantes, foi possível observar relatos de questões referentes às trocas de experiências promovidas e ao autoconhecimento gerado durante o processo. A Participante J (2017) afirmou que as atividades "envolveram desde um processo de autoconhecimento até de conhecer o próximo". Algumas outras reações obtidas sobre o processo foram "Foi ótimo nos conhecermos melhor e isso naturalmente gerará muitos frutos no futuro (PARTICIPANTE A, 2017) e "A interação é ótima" (PARTICIPANTE I, 2017). 
Ferramentas para a compreensão do conhecimento tácito de indivíduos

BARAUNA, D. et al.

\section{CONCLUSÃO}

Concluiu-se que, a combinação das ferramentas, jogo de perguntas pessoais, mapa de empatia e storytelling, tem potencial de uso para a compreensão breve do conhecimento tácito de indivíduos.

Contudo, foi observado que características pessoais negativas e características relacionais dos indivíduos, ainda foram de difícil extração por meio das ferramentas aplicadas, sendo, necessário o estudo de questões orientativas ou ferramentas complementares. Talvez a aplicação de uma matriz FOFA (Força, Oportunidades, Fraquezas e Ameaças) do ponto de vista do indivíduo e seu contexto seja uma possibilidade de ferramenta complementar.

No mais, a aplicação das ferramentas, como uma dinâmica, antes de um processo de criação de conhecimento, mostrou-se relevante na medida em que se gerou um autoconhecimento e conhecimento mútuo nos participantes, facilitando a atividade de socialização da espiral do conhecimento. 
Projética, Londrina, v.11, n.1, p. 194-219, abril 2020

\section{REFERÊNCIAS}

1. ASSOCIAÇÃO BRASILEIRA DAS ENTIDADES FECHADAS DE PREVIDÊNCIA COMPLEMENTAR - ABRAPP. Guia para modelo de avaliação de desempenho. São Paulo: ABRAPP, 2013.

2. BATOCCHIO, Antônio; BIAGIO, Luiz Arnaldo. A importância da avaliação do capital intelectual na administração estratégica. In: ENCONTRO NACIONAL DE ENGENHARIA DE PRODUÇÃO, 19., 1999, Rio de Janeiro. Anais [...]. Rio de Janeiro: Associação Brasileira de Engenharia de Produção, 1999. v. 19.

3. BEBER, Bernadétte; SILVA, Eduardo; BONFIGLIO, Simoni U. Metacognição como processo da aprendizagem. Revista Psicopedagogia, São Paulo, v. 3, n. 95, p. 144-151, 2014.

4. COLOSSI, Nelson; BAADE, Joel Haroldo. Interdisciplinaridade e a teoria geral dos sistemas. Revista Visão: Gestão Organizacional, Caçador, v. 4, n. 1, p. 7-21, jun. 2015.

5. COUTINHO, Clara Pereira; LISBÔA, Eliana Santana. Sociedade da informação, do conhecimento e da aprendizagem: desafios para educação no século XXI. Revista de Educação, Lisboa, v. 18, n. 1, p. 5-22, 2011.

6. DÍAZ, Félix. O processo de aprendizagem e seus transtornos. Salvador: EDUFBA, 2011.

7. FABELA, Sérgio. A vida toda para aprender. Psicologia.pt: o Portal dos Psicólogos, Porto, 30 dez. 2005. Disponível em: https://www.psicologia.pt/artigos/ textos/A0321.pdf. Acesso em: 2 dez. 2015. 
Ferramentas para a compreensão do conhecimento tácito de indivíduos

BARAUNA, D. et al.

8. FLEURY, Maria Tereza Leme; FLEURY, Afonso. Construindo o conceito de competência. Revista de Administração Contemporânea, Curitiba, v. 5, n. esp., p. 183-196, 2001. Número especial.

9. GASQUE, Kelley Gonçalves Dias; TESCAROLO, Ricardo. Sociedade da aprendizagem: informação, reflexão e ética. Ciência da Informação, Brasília, v. 33, n. 3, p. 35-40, set./dez. 2004.

10. GRAY, Dave. Empathy map. 2009. Disponível em: http://gamestorming.com/ empathy-map/. Acesso em: 3 maio 2016.

11. HASHIMOTO, Alberto Nobuyuki. O que é conhecimento. 2003. Disponível em: https://kmol.pt/artigos/2003/02/01/o-que-e-conhecimento/. Acesso em: 5 out. 2017.

12. KOFMAN, Fredy. Metamanagement: a nova consciência dos negócios. São Paulo: Willis Harman House, 2002. v. 3.

13. MOREIRA, Marco Antônio. ¿Al afinal, qué es aprendizaje siginificativo? Qurriculum: Revista de Teoría, Investigación y Práctica Educativa, La Laguna, n. 25, p. 29-56, marzo 2012.

14. NONAKA, Ikujiro; KONNO, Noboru. The concept of "Ba": building a foundation for knowledge creation. California Management Review, Berkeley, v. 40, n. 3, p. 40-54, 1998.

15. NONATO, Luiz Fernando Costa. Inovação na era do conhecimento. TecHoje: uma Revista de Opinião, Belo Horizonte, art. 572, 4 fev. 2009. Disponível em: http://www.techoje.com.br/site/techoje/categoria/impressao_artigo/572. Acesso em: 12 dez. 2015.

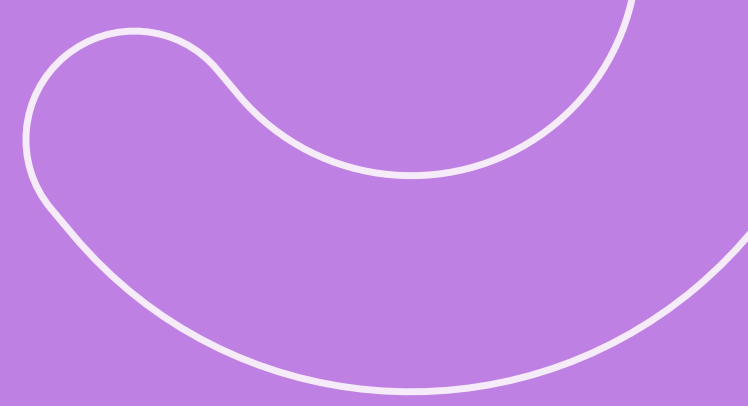


Projética, Londrina, v.11, n.1, p. 194-219, abril 2020

16. PACHECO, Fernando Flávio, PEREIRA, Heitor José, BASTOS JÚNIOR, Paulo Alberto (org.). Gestão do conhecimento: uma experiência para o sucesso empresarial. Curitiba: Champagnat, 2001.

17. POZO, Juan Ignacio. A sociedade da aprendizagem e o desafio de converter informação em conhecimento. São Paulo: UDEMO: Sindicato de Especialistas de Educação. do Magistério Oficial do Estado, 2007. Replanejamento das Escolas. Projeto pedagógico, 9, p. 34-36. Disponível em: http://www.udemo. org.br/A\%20Sociedade.pdf. Acesso em: 5 out. 2017.

18. POZO, Juan Ignacio. Aprendizes e mestres: a nova cultura da aprendizagem. Porto Alegre: Artmed, 2002.

19. REICHERT, Inês Caroline. A educação para a cidadania numa sociedade da informação pós-capitalista. Direito em Revista, Francisco Beltrão, v. 1, p. 133-157, 2002.

20. RIES, Eric. The lean startup: how today's entrepreneurs use continuous innovation to create radically successful businesses. New York: Currency, 2011.

21. RUSSO, Rosária de Fátima Segger Macri; RUIZ, Jose Moreno; CUNHA, Rosana Paulo da. Liderança e influência nas fases da gestão de projetos. Production, São Paulo, v. 15, n. 3, p. 362-375, set./dez. 2005.

22. SALMON, Christian. Storytelling: la fabbrica delle storie. Roma: Fazi, 2008.

23. SILVA, Sérgio Luís. Gestão do conhecimento: uma revisão crítica orientada pela abordagem da criação do conhecimento. Ciência da Informação, Brasília, v. 33, n. 2, p. 143-151, 2004. 
Ferramentas para a compreensão do conhecimento tácito de indivíduos

BARAUNA, D. et al.

24. TORQUATO, Mirian; WILLERDING, Inara Antunes Vieira; LAPOLLI, Édis Mafra. A ferramenta design Thinking: uma estratégia da gestão empreendedora da inovação para o despertar criativo em organizações. In: CONGRESSO LATINO-IBEROAMERICANO DE GESTÃO DA TECNOLOGIA, 16., 2015, Porto Alegre. Anais [...]. Porto Alegre: UFRGS, 2015. Disponível em: http://altec2015.nitec. co/altec/papers-br.html. Acesso em: 5 out. 2017.

25. VASCONCELLOS, Celso S. Formação didática do educador contemporâneo: desafios e perspectivas. In: UNIVERSIDADE ESTADUAL PAULISTA. Pró-Reitoria de Graduação. Caderno de formação: formação de Professores didática dos conteúdos. São Paulo: Cultura Acadêmica, 2011. v. 9, p. 33-58.

26. ZANGISKI, Marlene Aparecida da Silva Gonçalves; LIMA, Edson Pinheiro; COSTA, Sérgio Eduardo Gouvêa. Aprendizagem organizacional e desenvolvimento de competências: uma síntese a partir da gestão do conhecimento. Produto \& Produção, Porto Alegre, v. 10, n. 1, p. 54-74, 2009. 